\title{
Long-term Efficacy and Safety of Erenumab
}

\section{Results From 64 Weeks of the LIBERTY Study}

Peter J. Goadsby, MD, Uwe Reuter, MD, Michel Lanteri-Minet, MD, Gabriel Paiva da Silva Lima, MD, Peggy Hours-Zesiger, PhD, Chrystel Fernandes, PhD, Shihua Wen, PhD, Nadia Tenenbaum, MD, Aditi Kataria, MPharmacy, Michel D. Ferrari, MD, and Jan Klatt, MD

Neurology ${ }^{\circledR}$ 2021;96:e2724-e2735. doi:10.1212/WNL.0000000000012029

\section{Abstract}

\section{Objective}

To report the efficacy and safety of erenumab among patients with episodic migraine (EM) who were unsuccessful on 2 to 4 preventive treatments observed at week 64 of the open-label extension phase (OLEP) of A Study Evaluating the Effectiveness of AMG 334 Injection in Preventing Migraines in Adults Having Failed Other Therapies (LIBERTY) study (ClinicalTrials.gov NCT03096834).

\section{Methods}

The OLEP, evaluating monthly erenumab $140 \mathrm{mg}$ for 3 years, enrolled 240 patients who completed the double-blind treatment phase (DBTP) of 12 weeks during which they received placebo or erenumab $140 \mathrm{mg}$ subcutaneous injections every 4 weeks as monotherapy. Efficacy outcomes were evaluated through the initial 52 weeks of OLEP (from DBTP baseline to total 64 weeks) in the overall population, patients receiving erenumab in DBTP, and patients from the DBTP placebo arm who switched to erenumab in OLEP. Endpoints included reduction of $\geq 50 \%$ in monthly migraine days (MMD) from DBTP baseline and change in MMD from DBTP baseline, Headache Impact Test score, and Migraine Physical Function Impact Diary score (Physical Impairment and Everyday Activities).

\section{Results}

Altogether, the week 52 visit of the OLEP was completed by 204 of 240 (85.0\%) patients. Among patients continuing erenumab, the $50 \%$ responder rate increased from $29.9 \%$ at weeks 9 to 12 to $44.3 \%$ at weeks 61 to 64 . The $50 \%$ responder rate in patients who initiated erenumab in the OLEP remained higher in the OLEP (50.0\% at week 61-64) than during DBTP (14.2\% at weeks 9-12) compared to patients in continuous erenumab arm. In the OLEP, the $50 \%$ responder rate for the overall population increased from weeks 13 to 16 until weeks 37 to 40 and then remained stable through weeks 61 to 64. Patients treated with erenumab in DBTP showed sustained effects on all efficacy outcomes; those initiating erenumab in the OLEP demonstrated continued improvement from week 13 onward. Adverse events (AEs) were reported, considering both treatment groups, by $\approx 80.8 \%$ (serious AEs by $6.7 \%$ ), $76.3 \%$ (5.9\%) in the continuing erenumab arm, and $85.2 \%$ $(7.4 \%)$ in those starting erenumab in OLEP. No deaths were reported.

\section{Conclusions}

In patients with EM who were unsuccessful on 2 to 4 prior preventive treatments, the LIBERTY study demonstrated sustained efficacy on erenumab monotherapy treatment through 64 weeks in both treatment arms. Safety of erenumab was consistent with that observed in previous clinical trials.

\author{
Correspondence \\ Dr. Goadsby \\ peter.goadsby@kcl.ac.uk
}

MORE ONLINE

$\rightarrow$ Class of Evidence

Criteria for rating

therapeutic and diagnostic studies

NPub.org/coe

\section{Trial Registration Information}

ClinicalTrials.gov Identifier: NCT03096834.

From the NIHR-Wellcome Trust King's Clinical Research Facility (P.J.G.), King's College London, UK; Department of Neurology (P.J.G.), University of California, Los Angeles; Department of Neurology (U.R.), Charité Universitätsmedizin Berlin, Germany; Pain Department and FHU InovPain (M.L.-M.), CHU Nice-Côte Azur Université, France; INSERM U1107 Migraine and Trigeminal Pain (M.L.-M.), Auvergne University, Clermont-Ferrand, France; Amgen Inc (G.P.d.S.L.), Thousand Oaks, CA; Novartis Pharma AG (P.H.-Z., C.F., J.K.), Basel, Switzerland; Novartis Pharmaceutical Corp (S.W., N.T.), East Hanover, NJ; Novartis Healthcare Pvt. Ltd. Hyderabad (A.K.), India; and Department of Neurology (M.D.F.), Leiden University Medical Centre, the Netherlands.

Go to Neurology.org/N for full disclosures. Funding information and disclosures deemed relevant by the authors, if any, are provided at the end of the article. 


\section{Glossary}

$\mathbf{A E}=$ adverse event $\mathbf{C G R P}=$ calcitonin gene-related peptide; $\mathbf{C M}=$ chronic migraine; $\mathbf{D B T P}=$ double-blind treatment phase; EA = everyday activities; eDiary = electronic diary; EM = episodic migraine; HIT-6 = Headache Impact Test; LIBERTY = A Study Evaluating the Effectiveness of AMG 334 Injection in Preventing Migraines in Adults Having Failed Other Therapies; MMD = monthly migraine days; MPFID = Migraine Physical Function Impact Diary; OLEP = open-label extension phase; PI = physical impairment; SAE = serious AE; STRIVE = Study to Evaluate the Efficacy and Safety of Erenumab (AMG 334) in Migraine Prevention.

\section{Classification of Evidence}

The current study provides Class IV evidence on data from patients with EM that erenumab is safe and provides sustained efficacy at 52 weeks.

Erenumab, being a fully human monoclonal antibody, binds with the calcitonin gene-related peptide (CGRP) receptor to block its activation as it plays a role in migraine. ${ }^{1,2}$ Erenumab has proved to be efficacious and safe in episodic migraine (EM) ${ }^{3-5}$ or chronic migraine $(\mathrm{CM})^{6}$ thorough randomized studies.

The longer-term safety and efficacy profile of erenumab in patients with EM is being evaluated in a 5-year, open-label study (NCT01952574), and an interim analysis at $\geq 3$ years of follow-up was published recently. ${ }^{7}$ The efficacy and safety of erenumab administered in different doses after 1 year of treatment have been evaluated in the active treatment phase of the Study to Evaluate the Efficacy and Safety of Erenumab (AMG 334) in Migraine Prevention (STRIVE) study ${ }^{8}$ and in the 1-year open-label treatment phase in patients with $\mathrm{CM}^{9}$ Erenumab demonstrated sustained efficacy with long-term treatment and a safety profile comparable to that of placebo.

The results from the double-blind treatment phase (DBTP) of the phase 3b A Study Evaluating the Effectiveness of AMG 334 Injection in Preventing Migraines in Adults Having Failed Other Therapies (LIBERTY) study demonstrated efficacy of erenumab $140 \mathrm{mg}$ in patients with EM who were unsuccessful on 2 to 4 prior preventive treatments. ${ }^{10}$ These findings are in line with study results from other CGRP pathway antagonists, fremanezumab ${ }^{11}$ and galcanezumab. ${ }^{12}$ The studies highlight the need for longerterm data because adherence to preventives is poor ${ }^{13}$; thus, clinicians can discuss with patients on this new category of medications. The 3-year open-label extension phase (OLEP) of the LIBERTY study is currently ongoing. Here, we report the longerterm efficacy and safety of erenumab in patients with EM who were unsuccessful on 2 to 4 previous preventives and completed 64 weeks in the LIBERTY study (52 weeks of the OLEP).

\section{Methods}

\section{Study Design}

The design of the LIBERTY study is presented in figure 1. In the 12-week DBTP, patients with EM were randomized in a 1: 1 ratio to receive either placebo or erenumab $140 \mathrm{mg}$ monotherapy, both administered subcutaneously once every 4 weeks for 12 weeks ${ }^{10}$ Patients who completed the 12-week DBTP were eligible to participate in an ongoing 3-year OLEP. Two injections of open-label erenumab $70 \mathrm{mg}$ each (equaling 140-mg total dose) were administered by qualified study staff at each dosing visit during the 52-week OLEP. No other preventive comedications were allowed; that is, patients were on erenumab monotherapy. The aim of the DBTP was to compare the efficacy and tolerability of erenumab with that of placebo in patients with EM who had earlier not adequately responded to 2 to 4 preventive treatments or who were not able to tolerate these treatments. The results from the DBTP of the LIBERTY study have been reported previously. ${ }^{10}$ This article presents the efficacy and safety of erenumab from 64 weeks of treatment including 52 weeks of the OLEP from the LIBERTY study.

\section{Inclusion/Exclusion Criteria}

Eligibility criteria for the LIBERTY study were reported previously. ${ }^{10}$ Briefly, the main inclusion criteria included age of 18 to 65 years, a diagnosis of EM (4-14 monthly migraine days $[\mathrm{MMD}]) .{ }^{14}$ Patients were to have (1) failed 2 to 4 prior attempts to preventive treatment with the following agents: metoprolol or propranolol, flunarizine, topiramate, amitriptyline, valproate/or divalproex, lisinopril, venlafaxine, candesartan, or locally approved preventive agents (indoramin in France; cinnarizine in the Czech Republic; oxetorone in France; nadolol in Spain; and pizotifen in Austria, the Czech Republic, France, the Netherlands, Sweden, and the United Kingdom); (2) failed 1 and failed or deemed not suitable for another preventive treatment such as propranolol or metoprolol, topiramate, or flunarizine; and (3) failed or deemed not suitable for valproate or divalproex. Treatment failure (efficacy and safety) and unsuitability to any medication were assessed on the basis of the patient's medical history and physicians' medical judgment. ${ }^{10}$

Patients $\geq 50$ years of age at migraine onset, nursing, or pregnant; those with a history of hemiplegic migraine headache, cluster headache, psychiatric disorder or seizure, active chronic pain, any malignancy, or hepatic disease; patients 
using a preventive treatment for migraine within 5 times the drug's half-life before baseline or a device or procedure within the month before baseline; or those receiving botulinum toxin A treatment within the 4 months before initiation/during the baseline phase in the head or neck were excluded from the study. Patients with preexisting cerebrovascular or cardiovascular disease/surgery within the 12 months before screening and those with medication overuse for any condition in the month before or during the baseline period were also excluded.

\section{Outcomes}

The primary and secondary efficacy endpoints of the DBTP of LIBERTY study have been reported previously. ${ }^{10}$ Efficacy outcomes in the OLEP included achievement of $\geq 50 \%$ reduction in MMD compared to DBTP baseline, change in MMD from DBTP baseline, change in Headache Impact Test (HIT-6) total score, and change in everyday activities (EA) and physical impairment (PI) as measured by Migraine Physical Function Impact Diary (MPFID) from DBTP baseline. Efficacy outcomes were measured monthly during the first 3 months of the OLEP and then only for the last month of each quarter through week 64 .

HIT-6 is a short-form self-administered questionnaire based on the Internet-HIT question pool that evaluates how often headaches affect activities or cause distress, using the functionally relevant domains. ${ }^{15}$ Six domains assess the impact of pain severity. Functional impairment in patients with migraine was measured with change in HIT-6 total score from baseline to week 12 during the DBTP and to weeks 16, 36, 48, and 60 in the OLEP.

The MPFID is a self-administered, 13-item instrument measuring impact on EA (7 items), impact on PI (5 items), and overall impact (1 stand-alone, global item). ${ }^{16}$ For each domain, the scores were computed as the sum of the item responses, and the sum was rescaled to a scale from 0 to 100 , with higher scores representing higher burden. Patients completed the MPFID every day using an electronic diary (eDiary), with a recall period of 24 hours only.

Safety and tolerability of erenumab were evaluated by monitoring adverse events (AEs), vital signs, physical examinations, laboratory evaluations, blood pressure/heart rate, and ECG, and AEs were coded according to the Medical Dictionary for Regulatory Activities version 21.1, and severity was graded with the Common Terminology Criteria for Adverse Events version 4.03 .

\section{Statistical Analysis}

The open-label analysis set included all patients being administered $\geq 1$ dose of erenumab in the OLEP. This analysis set was used for summarizing data collected during the OLEP. For analyses of efficacy parameters during the OLEP, summary descriptive statistics by each treatment arm were tabulated at each visit. For continuous endpoints, the descriptive statistics included number of patients, mean, and SD. For categorical endpoints, frequency and percentage were used. No formal statistical testing was performed. The demographics summary generated for the DBTP was rerun on the subset of patients who entered the OLEP and received $\geq 1$ dose of erenumab in the OLEP. The number of $50 \%$ responders at each visit of OLEP was tabulated by treatment arm and responder status (50\% responder, 50\% nonresponder, missing) at week 12 .

Overall, exposure-adjusted participant incidence rate of AEs were summarized for all treatment-emergent AEs, serious AEs (SAE), and AEs leading to discontinuation of study treatment for the DBTP in the subset of patients who entered the OLEP. Summary of AEs during the OLEP compared to DBTP are also presented.

A temporary technical issue related to the use of the log pads for recording of daily headache was reported in July 2018 that resulted in the loss of data for a subset of patients and subsequently missing data for efficacy endpoints coming from eDiary. Approximately, one-third of the patients who were still ongoing in the OLEP had missing data for week 52 and 64 visits for endpoints based on daily eDiary and week 48 and 60 for HIT-6. Week 52 data based on daily eDiary were collected during week 49 to 52 (the eDiary log was dispensed on week 48). However, the HIT-6 questionnaire was filled in on the week 48 visit. This resulted in significantly lower number of data points reported for these visits. There was no impact on collection of safety data. Sensitivity analyses with different imputation techniques were performed on efficacy data to assess the impact of the missing data on the overall results. Only the data from patients who continued treatment with erenumab in the OLEP to week 64 were imputed. For the sensitivity analyses on the key efficacy endpoints (responder rate and HIT-6), 3 additional analyses (summary statistics by visit) were run on imputed data using 3 different methods of imputation: (1) multiple imputation assuming missing at random, (2) last observation carried forward, and (3) imputing the missing data using the mean value on previous time points (from OLEP).

\section{Standard Protocol Approvals, Registrations, and Patient Consents}

This study is registered with ClinicalTrials.gov (NCT03096834). All processes were reviewed and approved by institutional review boards at the site of participation. All centers complied with local regulations, and patients provided written informed consent. This study was conducted in agreement with International Council for Harmonisation Good Clinical Practice guidelines.

\section{Classification of Evidence}

The study provides Class IV evidence that for patients with EM who were unsuccessful on 2 to 4 prior preventive treatments, erenumab showed favorable treatment effects on 


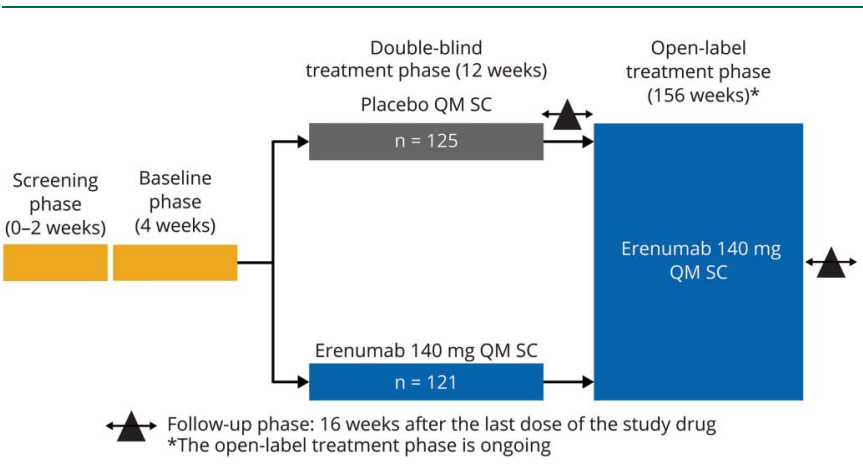

Follow-up phase 16 weeks after the last dose of the study drug. *The open-label extension phase (OLEP) is ongoing. LIBERTY = A Study Evaluating the Effectiveness of AMG 334 Injection in Preventing Migraines in Adults Having Failed Other Therapies; $n=$ Number of patients from each treatment arm in the double-blind treatment phase entering into the OLEP; $\mathrm{N}=$ Number of patients in each treatment arm in the DBTP; $\mathrm{QM}=$ once monthly; SC = subcutaneous. efficacy and safety parameters after 1 year of open-label treatment.

\section{Data Availability}

The data presented in this report are available by request from the author investigators or Novartis Pharma AG, the company sponsoring this clinical research.

\section{Results}

\section{Patient Disposition, Baseline Characteristics, and Primary Results}

Patients $(\mathrm{N}=246)$ were randomized to receive erenumab $140 \mathrm{mg}(\mathrm{n}=121)$ or placebo $(\mathrm{n}=125)$ in the LIBERTY study. Of these, 240 (97.6\%) completed the DBTP and entered the OLEP ( $\mathrm{n}=118$ patients on erenumab $140 \mathrm{mg}$ continued on erenumab $140 \mathrm{mg}$ and $\mathrm{n}=122$ for patients on placebo who switched to erenumab $140 \mathrm{mg}$ ). A total of 36 (15.0\%) patients discontinued OLEP before/on week 64: 17 (14.4\%) patients from the continuous erenumab arm and 19 (15.6\%) patients who switched from placebo to erenumab. The most common reasons for OLEP discontinuation were lack of efficacy $(n=19,7.9 \%)$, participant/guardian decision $(\mathrm{n}=11,4.6 \%)$, and AEs $(\mathrm{n}=4,1.7 \%)$ (figure 2$)$.
The treatment arms were well balanced in terms of baseline and disease characteristics (table 1). Among the patients who entered the OLEP, $>81.0 \%$ of patients were women, and $62.1 \%$ had $>2$ prior preventive treatment failures.

\section{Efficacy}

In the OLEP, the $50 \%$ responder rate for the overall population increased from weeks 13 to 16 until weeks 37 to 40 and then remained stable through weeks 61 to 64 (figure 3 ). Compared with erenumab $140 \mathrm{mg}$ in the DBTP, an increase in the $50 \%$ response rates was observed from weeks 17 to 20 onward for the overall population in the OLEP. Among patients continuing erenumab, the $50 \%$ responder rate increased from $29.9 \%$ at weeks 9 to 12 to $41.7 \%$ at weeks 21 to 24 and $44.3 \%$ at week 61 to 64 . The $50 \%$ responder rate in patients who initiated erenumab in the OLEP remained higher in the OLEP than during DBTP (weeks 9-12) compared to patients in the continuous erenumab arm who demonstrated slightly increased and stable response in OLEP (figure 3).

Among the 35 patients who responded to continued erenumab (patients on erenumab $140 \mathrm{mg}$ in DBTP who continued

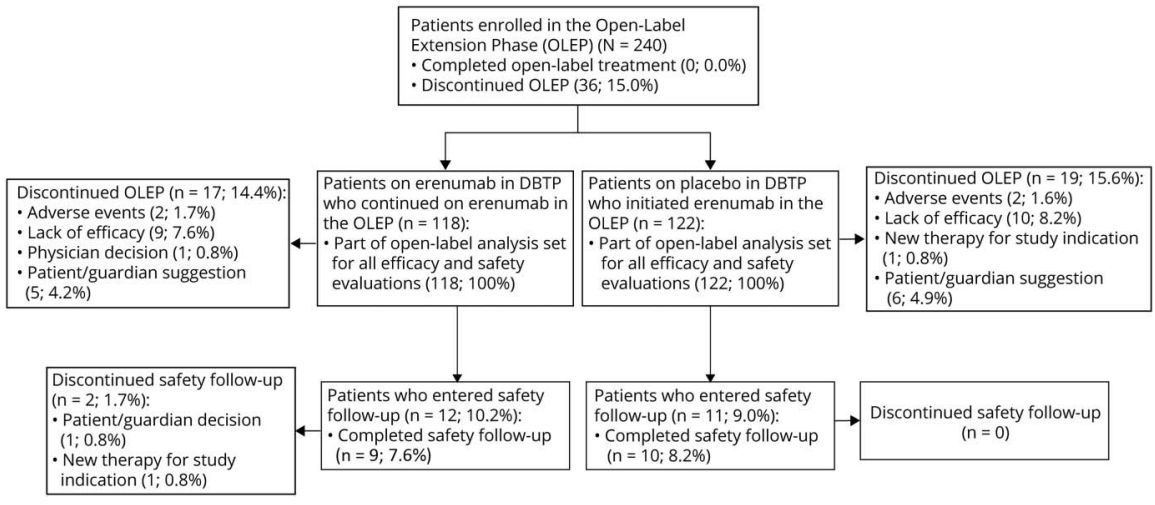


Table 1 Key Baseline and Demographic Characteristics of the Enrolled Patients in the OLEP of the LIBERTY Study (OpenLabel Analysis Set)

\begin{tabular}{|c|c|c|c|}
\hline Characteristics & $\begin{array}{l}\text { Patients on erenumab } 140 \mathrm{mg} \\
\text { in DBTP who continued erenumab } \\
\text { in OLEP }(\mathrm{N}=118)\end{array}$ & $\begin{array}{l}\text { Patients on placebo } \\
\text { in DBTP who initiated } \\
\text { erenumab in OLEP }(N=122)\end{array}$ & $\begin{array}{l}\text { Overall population } \\
\text { in OLEP }(\mathrm{N}=240)\end{array}$ \\
\hline Age, y & $44.6(10.6)$ & $44.4(10.5)$ & $44.5(10.5)$ \\
\hline \multicolumn{4}{|l|}{ Sex, n (\%) } \\
\hline Male & $22(18.6)$ & $22(18.0)$ & $44(18.3)$ \\
\hline Female & $96(81.4)$ & $100(82.0)$ & $196(81.7)$ \\
\hline \multicolumn{4}{|l|}{ Race, n (\%) } \\
\hline White & $109(92.4)$ & $112(91.8)$ & $221(92.1)$ \\
\hline Asian & $0(0.0)$ & $1(0.8)$ & $1(0.4)$ \\
\hline Unknown & $0(0.0)$ & $1(0.8)$ & $1(0.4)$ \\
\hline Other & $9(7.6)$ & $8(6.6)$ & $17(7.1)$ \\
\hline \multicolumn{4}{|l|}{ Ethnicity, n (\%) } \\
\hline Hispanic/Latino & $13(11.0)$ & $8(6.6)$ & $21(8.8)$ \\
\hline Not Hispanic/Latino & $97(82.2)$ & $103(84.4)$ & $200(83.3)$ \\
\hline Unknown & $8(6.8)$ & $11(9.0)$ & $19(7.9)$ \\
\hline Weight, kg & $72.8(14.4)$ & $72.0(15.9), n=121$ & $72.4(15.2), n=239$ \\
\hline BMI, $\mathrm{kg} / \mathrm{m}^{2}$ & $25.0(4.2)$ & $24.8(5.0), n=121$ & $24.9(4.6), n=239$ \\
\hline \multicolumn{4}{|c|}{ No. of previous unsuccessful preventive migraine treatments } \\
\hline$<2$ & $1(0.8)$ & $0(0.0)$ & $1(0.4)$ \\
\hline 2 & $42(35.6)$ & 48 (39.3) & $90(37.5)$ \\
\hline 3 & $43(36.4)$ & $51(41.8)$ & $94(39.2)$ \\
\hline 4 & $32(27.1)$ & $23(18.9)$ & 55 (22.9) \\
\hline \multicolumn{4}{|c|}{ Previous unsuccessful preventive medications, $\mathbf{n}(\%)$} \\
\hline Amitriptyline & $48(40.7)$ & $61(50.0)$ & $109(45.4)$ \\
\hline Candesartan & $26(22.0)$ & $26(21.3)$ & $52(21.7)$ \\
\hline Flunarizine & $29(24.6)$ & $37(30.3)$ & $66(27.5)$ \\
\hline Lisinopril & $2(1.7)$ & $0(0.0)$ & $2(0.8)$ \\
\hline Metoprolol & $46(39.0)$ & $48(39.3)$ & $94(39.2)$ \\
\hline Propranolol & $58(49.2)$ & $52(42.6)$ & $110(45.8)$ \\
\hline Topiramate & $102(86.4)$ & $102(83.6)$ & $204(85.0)$ \\
\hline Valproate & $43(36.4)$ & $25(20.5)$ & $68(28.3)$ \\
\hline Venlafaxine & $6(5.1)$ & $7(5.7)$ & $13(5.4)$ \\
\hline Others $^{a}$ & $9(7.6)$ & $13(10.7)$ & $22(9.2)$ \\
\hline MMD & $9.2(2.4)$ & $9.3(2.6)$ & $9.2(2.5)$ \\
\hline \multicolumn{4}{|l|}{ MMD by strata, $\mathbf{n}(\%)$} \\
\hline Stratum 1 (low): 4-7 & $34(28.8)$ & $36(29.5)$ & $70(29.2)$ \\
\hline Stratum 2 (high): 8-14 & $84(71.2)$ & $86(70.5)$ & $170(70.8)$ \\
\hline Monthly headache days & $10.0(2.6)$ & $10.1(2.6)$ & $10.0(2.6)$ \\
\hline
\end{tabular}


Table 1 Key Baseline and Demographic Characteristics of the Enrolled Patients in the OLEP of the LIBERTY Study (OpenLabel Analysis Set) (continued)

\begin{tabular}{|c|c|c|c|}
\hline Characteristics & $\begin{array}{l}\text { Patients on erenumab } 140 \mathrm{mg} \\
\text { in DBTP who continued erenumab } \\
\text { in OLEP }(\mathrm{N}=118)\end{array}$ & $\begin{array}{l}\text { Patients on placebo } \\
\text { in DBTP who initiated } \\
\text { erenumab in OLEP }(N=122)\end{array}$ & $\begin{array}{l}\text { Overall population } \\
\text { in OLEP }(N=240)\end{array}$ \\
\hline Disease duration of migraine, $y$ & $26.9(12.1)$ & $24.0(10.9)$ & $25.4(11.6)$ \\
\hline \multicolumn{4}{|l|}{ Aura, n (\%) } \\
\hline Present & 40 (33.9) & 45 (36.9) & $85(35.4)$ \\
\hline Not present & $78(66.1)$ & $77(63.1)$ & $155(64.6)$ \\
\hline \multicolumn{4}{|c|}{ Patient-reported outcomes of the enrolled patients in the LIBERTY study at baseline (Open-Label Analysis Set) } \\
\hline MPFID-EA score & $14.1(8.5)$ & $14.3(8.8)$ & $14.2(8.6)$ \\
\hline MPFID-PI score & $12.8(9.2)$ & $13.1(9.6)$ & $13.0(9.4)$ \\
\hline HIT-6 score & $62.3(4.1)$ & $62.5(5.1)$ & $62.4(4.6)$ \\
\hline \multicolumn{4}{|c|}{$\begin{array}{l}\text { Abbreviations: BMI = body mass index; DBTP = double-blind treatment phase; HIT-6 = Headache Impact Test; LIBERTY=A Study Evaluating the Effectiveness of } \\
\text { AMG } 334 \text { Injection in Preventing Migraines in Adults Having Failed Other Therapies; MMD = monthly migraine days; MPFID-EA = Migraine Physical Function } \\
\text { Impact Diary-Everyday Activities; MPFID-PI = Migraine Physical Function Impact Diary-Physical Impairment; } \mathrm{n}=\text { number of patients for whom data were } \\
\text { available at baseline; N = number of patients included in the analysis set; OLEP = open-label extension phase. } \\
\text { Data are mean (SD) or number (percent). } \\
\text { a Includes cinnarizine, indoramin, nadolol, oxetorone, and pizotifen. }\end{array}$} \\
\hline
\end{tabular}

erenumab in OLEP) at weeks 12 to 50,25 patients (71.4\%) responded at week 12 and at least 1 other visit during the OLEP, and 10 patients were responders at week 12 only: 50\% response (among the visits they performed with a nonmissing value for MMD). In addition, an analysis of the responders from the active arm in the DBTP, that is, continued erenumab (who achieved response in $2-3$ visits with $50 \%$ response [ $\mathrm{n}=$ 29 ] or who had responded at week 12 only [ $\mathrm{n}=10]$ or at week 12 and at least 1 other visit $[\mathrm{n}=25]$ ) showed a continuous response in the range of $70 \%$ to $75 \%$ to at least $50 \%$ of the visits during the OLEP (table 2).
Among the 29 patients who responded well to continuous erenumab during the OLEP ( $50 \%$ responder at 2 or 3 visits), 21 patients $(>70 \%)$ responded at half of the visits or more during the OLEP (among the visits they performed with a nonmissing value for MMD) (table 2).

A mean reduction in MMD from DBTP baseline was sustained in the overall population in the OLEP (figure 4). It improved over time (from weeks 13-16 to weeks 37-40) and then stabilized at the last 2 visits of assessment (weeks 49-52 and 61-64). Compared with the DBTP, a sharp mean

Figure 3 Responder Rate, $\geq 50 \%$ Reduction in Monthly Migraine Days

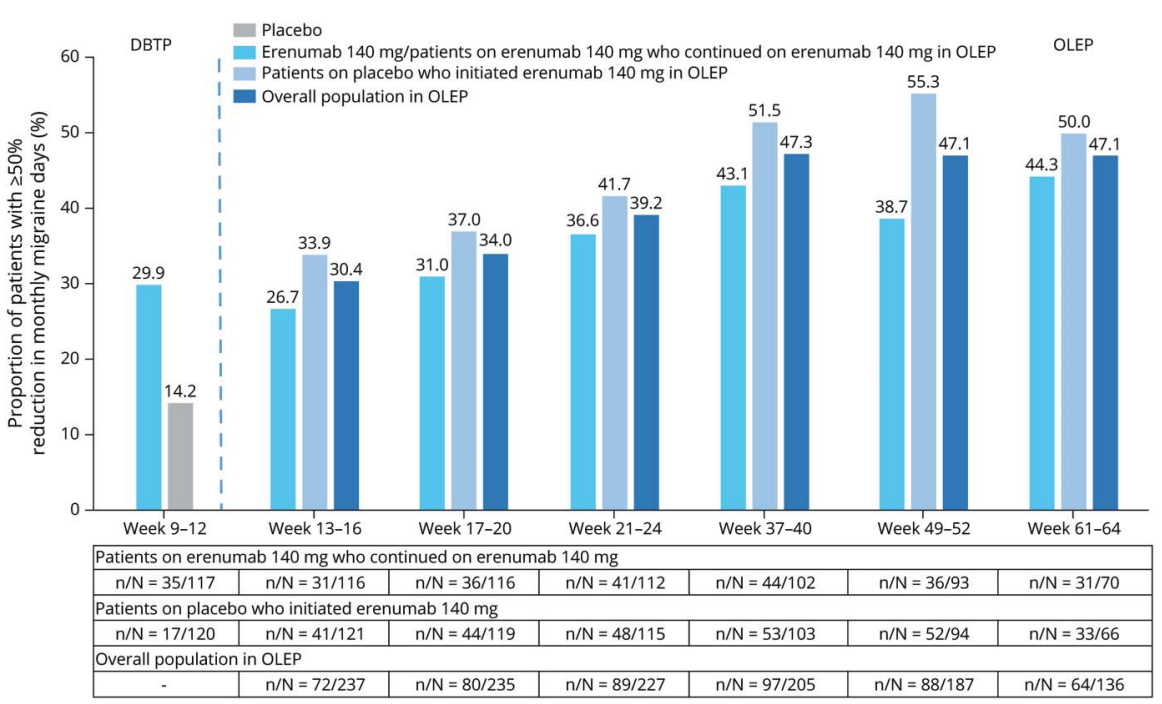

Data were calculated as number of responders (n)/total number of participants in the treatment arm with response variable defined $(\mathrm{N})$. OLEP $=$ open-label extension phase. 
Table 2 Achievement of at Least a 50\% Reduction in MMD During the OLEP: Shift Table by Treatment Arm and Responder Status During DBTP (Open-Label Analysis Set)

\begin{tabular}{|c|c|c|c|c|c|c|c|c|c|c|c|c|}
\hline \multirow[b]{3}{*}{ Criteria for DBTP } & \multicolumn{12}{|c|}{ Percentage of OLEP Visits Reaching 50\% Responder Criteria Among Visits with Nonmissing MMD Values } \\
\hline & \multicolumn{6}{|c|}{$\begin{array}{l}\text { Patients on erenumab } 140 \mathrm{mg} \text { in DBTP who continued erenumab in } \\
\text { OLEP, } \mathrm{n}(\%)\end{array}$} & \multicolumn{6}{|c|}{$\begin{array}{l}\text { Patients on placebo in DBTP who initiated } \\
\text { erenumab in OLEP, } \mathrm{n}(\%)\end{array}$} \\
\hline & Total & 0 & $\geq 30 \%$ & $\geq 50 \%$ & $\geq 80 \%$ & $100 \%$ & Total & 0 & $\geq 30 \%$ & $\geq 50 \%$ & $\geq 80 \%$ & $100 \%$ \\
\hline $\begin{array}{l}0 \text { Visits with } 50 \% \\
\text { response }\end{array}$ & 62 & 32 (51.6) & $14(22.6)$ & $10(16.1)$ & $3(4.8)$ & $0(0.0)$ & 97 & $33(34.0)$ & $49(50.5)$ & $38(39.2)$ & $17(17.5)$ & $10(10.3)$ \\
\hline $\begin{array}{l}1 \text { Visit with } 50 \% \\
\text { response }\end{array}$ & 27 & $7(25.9)$ & $13(48.1)$ & $9(33.3)$ & $3(11.1)$ & $0(0.0)$ & 12 & $3(25.0)$ & $8(66.7)$ & $6(50.0)$ & $2(16.7)$ & $0(0.0)$ \\
\hline $\begin{array}{l}2 \text { Visits with } 50 \% \\
\text { response }\end{array}$ & 17 & $1(5.9)$ & $14(82.4)$ & 12 (70.6) & $7(41.2)$ & $6(35.3)$ & 10 & $0(0.0)$ & $10(100.0)$ & $8(80.0)$ & $7(70.0)$ & $4(40.0)$ \\
\hline $\begin{array}{l}3 \text { Visits with } 50 \% \\
\text { response }\end{array}$ & 12 & $0(0.0)$ & $12(100.0)$ & $9(75.0)$ & $8(66.7)$ & $7(58.3)$ & 2 & $0(0.0)$ & $2(100.0)$ & $2(100.0)$ & $1(50.0)$ & $1(50.0)$ \\
\hline $\begin{array}{l}\text { At least } 1 \text { visit with } \\
50 \% \text { response }\end{array}$ & 56 & $8(14.3)$ & $39(69.6)$ & $30(53.6)$ & $18(32.1)$ & $13(23.2)$ & 24 & $3(12.5)$ & $20(83.3)$ & $16(66.7)$ & $10(41.7)$ & $5(20.8)$ \\
\hline $\begin{array}{l}\text { At least } 2 \text { visits with } \\
50 \% \text { response }\end{array}$ & 29 & $1(3.4)$ & $26(89.7)$ & $21(72.4)$ & $15(51.7)$ & $13(44.8)$ & 12 & $0(0.0)$ & $12(100)$ & $10(83.3)$ & $8(66.7)$ & $5(41.7)$ \\
\hline $\begin{array}{l}50 \% \text { Responder at } \\
\text { week } 12 \text { only }\end{array}$ & 10 & $1(10.0)$ & $8(80.0)$ & $7(70.0)$ & $2(20.0)$ & $0(0.0)$ & 6 & $2(33.3)$ & $4(66.7)$ & $2(33.3)$ & $0(0.0)$ & $0(0.0)$ \\
\hline $\begin{array}{l}50 \% \text { Responder at } \\
\text { week } 12 \text { and at } \\
\text { least } 1 \text { other visit }\end{array}$ & 25 & $1(4.0)$ & $22(88.0)$ & $18(72.0)$ & $13(52.0)$ & $11(44.0)$ & 11 & $0(0.0)$ & $11(100)$ & 9 (81.8) & 7 (63.6) & $5(45.5)$ \\
\hline
\end{tabular}

Abbreviations: DBTP = double-blind treatment phase; MMD = monthly migraine days; OLEP = open-label extension phase.

We define $50 \%$ responder as achievement of at least a $50 \%$ reduction in MMD.

reduction in MMD was observed from weeks 9-12 (-0.24) to $13-16$ (-2.5) followed by a continuous reduction in MMD until weeks 49-52 (-4.3) in the group of patients who switched to erenumab from placebo in OLEP. The reduction in MMD was overall sustained in the erenumab continued arm (figure 4).

In the OLEP, a mean reduction in the MPFID-PI and MPFID-EA scores from baseline was observed over time from weeks 13 to 16 to 37 to 40 ; this stabilized over the last 2 points of assessment, that is, weeks 49 to 52 and 61 to 64 in the overall population (table 3). The MPFID-PI and MPFID-EA scores were lower in week 37 to 40 and after visits compared with that observed at the DBTP endpoint.

The mean (SD) HIT-6 score at baseline for the overall population was 62.4 (4.6). Patients who started on erenumab $140 \mathrm{mg}$ in the OLEP showed improved reduction in daily impact of headache measured by the HIT- 6 total score at all visits. The reduction in HIT-6 total score was sustained in patients on continuous erenumab at all visits (table 3). An overall

Figure 4 Change in Monthly Migraine Days From Baseline Until Week 64 of the OLEP

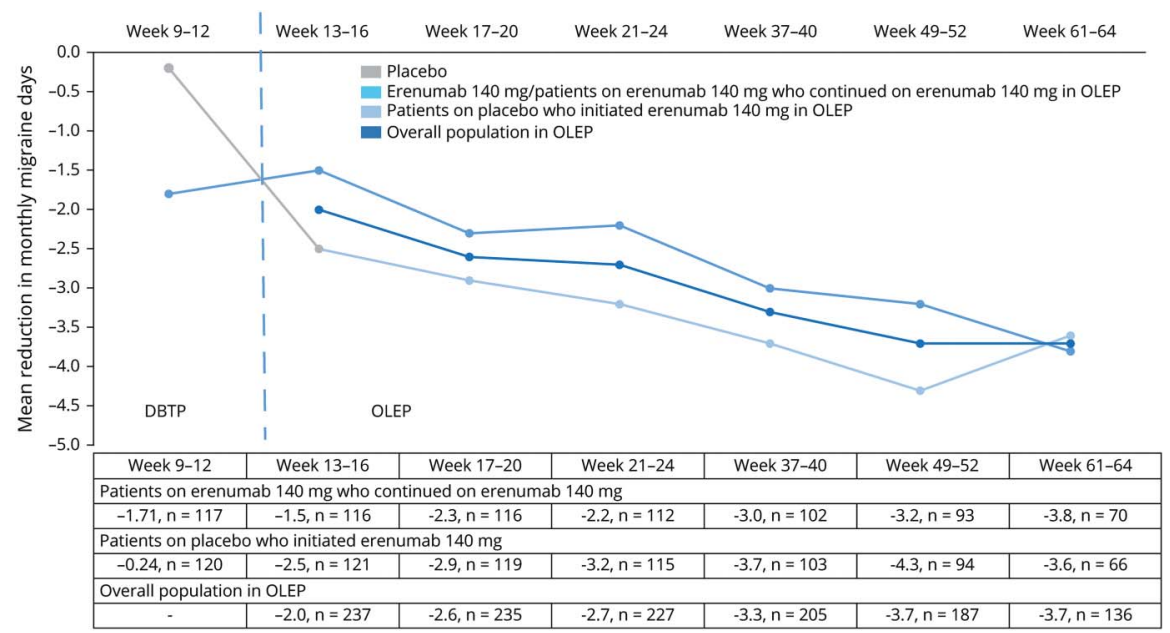

DBTP = double-blind treatment phase; $\mathrm{n}=$ total number of participants in the treatment arm with response variable defined; OLEP = openlabel extension phase. 
reduction in HIT-6 score was observed in the overall population from the DBTP endpoint (week 12) (mean [SD] 58.7 [7.0], mean $[\mathrm{SD}]$ change from baseline $-3.7[6.4]$ ) to the last visit at week 60 (mean [SD] 53.3 [8.3], mean [SD] change from baseline -9.0 [8.7]). However, a sharper decline in score was observed from weeks 12 (mean [SD] 60.2 [6.6], mean [SD] change from baseline $-2.3[5.9]$ ) to the last visit at week 60 (mean [SD] 52.4 [9.2], mean [SD] change from baseline -9.7 [10.0]) among patients who switched to erenumab in the OLEP (table 3).

Sensitivity analyses revealed results in all explored efficacy endpoints similar to those observed in the last 2 visits for assessments.

The values for $\geq 50 \%$ reduction from baseline in MMD during week 60 to 64 and change from baseline in HIT-6 at week 60 did not change the overall trends with erenumab, regardless of the missing data imputation method used (table 4).

\section{Safety}

Overall, during the OLEP, 194 (80.8\%) patients had treatment-emergent AEs, of which $90(76.3 \%)$ are from the continuous erenumab arm and 104 (85.2\%) initiated erenumab. The exposure-adjusted patient incidence rate for treatment-emergent AEs was 242.9 per 100 patient-years for the overall population and 200.2 and 297.9 per 100 patientyears for the continuous erenumab arm and those who initiated erenumab in the OLEP, respectively. In the DBTP, 70 (59.3\%) patients in the erenumab arm and $68(55.7 \%)$ patients in the placebo arm had treatment-emergent AEs; the exposure-adjusted patient incidence rates were 402.6 and 377.9 per 100 patient-years for erenumab and placebo, respectively. These values were higher than those observed in the OLEP.

Table 5 summarizes the most common AEs during the OLEP and the DBTP. In the OLEP, nasopharyngitis, experienced by $74(30.8 \%)$ patients (incidence rate 41.4 per 100 patient-years), was the most commonly reported AE followed by influenza, experienced by 31 (12.9\%) patients (incidence rate of 14.6 per 100 patient-years), and back pain, experienced by 18 (7.5\%) patients ( 8.2 per 100 patient-years), in the overall population.

Treatment-emergent SAEs were reported in $16(6.7 \%)$ patients of the overall population (exposure-adjusted incidence

Table 3 Other Observed Efficacy Outcome Measures in Weeks 13 to 64 of the LIBERTY Study (Open-Label Analysis Set)

\begin{tabular}{|c|c|c|c|c|}
\hline Outcomes & Time Point, wk & $\begin{array}{l}\text { Patients on erenumab } 140 \mathrm{mg} \\
\text { who continued on erenumab } \\
140 \mathrm{mg} \text { in OLEP }(\mathrm{N}=118)\end{array}$ & $\begin{array}{l}\text { Patients on placebo who } \\
\text { initiated erenumab } 140 \mathrm{mg} \text { in } \\
\text { OLEP }(\mathrm{N}=122)\end{array}$ & $\begin{array}{l}\text { Overall population } \\
(\mathrm{N}=\mathbf{2 4 0})\end{array}$ \\
\hline \multirow{5}{*}{$\begin{array}{l}\text { Change from DBTP baseline in } \\
\text { HIT-6 score }\end{array}$} & 12 & $-5.2(6.6), n=116$ & $-2.3(5.9), n=122$ & - \\
\hline & 16 & $-5.9(6.6), n=114$ & $-6.9(7.6), n=120$ & $-6.4(7.1), n=234$ \\
\hline & 36 & $-7.9(8.2), n=103$ & $-8.6(9.0), n=105$ & $-8.3(8.6), n=208$ \\
\hline & 48 & $-7.9(7.6), n=97$ & $-10.6(9.2), \mathrm{n}=99$ & $-9.2(8.6), n=196$ \\
\hline & 60 & $-8.5(7.4), n=88$ & $-9.7(10.0), n=82$ & $-9.0(8.7), n=170$ \\
\hline \multirow{5}{*}{$\begin{array}{l}\text { Change from DBTP baseline in } \\
\text { MPFID-PI score }\end{array}$} & $9-12$ & $-2.0(8.8), n=117$ & $1.3(8.9), n=120$ & - \\
\hline & $13-16$ & $-1.3(8.5), n=116$ & $-2.4(8.7), n=121$ & $-1.9(8.6), n=237$ \\
\hline & $37-40$ & $-3.2(8.7), n=102$ & $-4.7(8.6), n=103$ & $-3.9(8.7), n=205$ \\
\hline & $49-52$ & $-4.6(7.8), n=93$ & $-5.5(8.7), n=94$ & $-5.1(8.2), n=187$ \\
\hline & $61-64$ & $-5.2(6.9), n=70$ & $-4.5(8.4), n=66$ & $-4.8(7.7), n=136$ \\
\hline \multirow{5}{*}{$\begin{array}{l}\text { Change from DBTP baseline in } \\
\text { MPFID-EA score }\end{array}$} & $9-12$ & $-3.3(8.8), n=117$ & $0.4(8.9), n=120$ & - \\
\hline & $13-16$ & $-2.7(9.0), n=116$ & $-3.7(8.5), n=121$ & $-3.2(8.7), n=237$ \\
\hline & $37-40$ & $-4.6(8.8), n=102$ & $-5.5(8.8), n=103$ & $-5.0(8.8), n=205$ \\
\hline & $49-52$ & $-5.7(7.6), n=93$ & $-6.7(8.5), n=94$ & $-6.2(8.1), \mathrm{n}=187$ \\
\hline & $61-64$ & $-6.6(7.7), n=70$ & $-5.1(9.4), n=66$ & $-5.9(8.6), n=136$ \\
\hline
\end{tabular}

Abbreviations: DBTP = double-blind treatment phase; HIT-6 = Headache Impact Test; LIBERTY = A Study Evaluating the Effectiveness of AMG 334 Injection in Preventing Migraines in Adults Having Failed Other Therapies; MPFID-EA = Migraine Physical Function Impact Diary-Everyday Activity; MPFID-PI = Migraine Physical Function Impact Diary-Physical Impairment; $\mathrm{N}=$ Number of subjects in each treatment arm; $\mathrm{n}=$ Number of subjects with non missing score at each visit; OLEP = open-label extension phase.

Data are mean (SD) unless otherwise stated.

a HIT-6 total score was assessed by visit. 
Table 4 Results of Sensitivity Analyses for 50\% Reduction From Baseline in MMD and Change From Baseline in HIT-6 Scores

\begin{tabular}{lll}
\hline & $\begin{array}{l}\text { Proportion for } \mathbf{5 0 \%} \\
\text { responder }(\geq 50 \% \text { reduction } \\
\text { in MMD from baseline } \\
\text { during week } 60-64), \%\end{array}$ & $\begin{array}{l}\text { Change from } \\
\text { baseline in HIT-6 } \\
\text { score at week } 60\end{array}$ \\
\hline Main results & 44.3 & -9.0 \\
\hline $\begin{array}{l}\text { Sensitivity } \\
\text { analyses } \\
\text { results by } \\
\text { LOCF }\end{array}$ & 44.6 & -9.2 \\
\hline $\begin{array}{l}\text { Sensitivity } \\
\text { analyses } \\
\text { results by MCF }\end{array}$ & 41.7 & \\
\hline $\begin{array}{l}\text { Sensitivity } \\
\text { analyses } \\
\text { results by MI3 }\end{array}$ & 42.4 & -8.8 \\
\hline
\end{tabular}

Abbreviations: HIT-6 = Headache Impact Test; LOCF = last observation carried forward; $\mathrm{MCF}=$ mean carried forward; $\mathrm{MI}=$ multiple imputation; $\mathrm{MMD}=$ monthly migraine days.

rate 7.2 per 100 patient-years). This was nearly similar to the observations of DBTP (2 [1.7\%], incidence rate 7.2 per 100 patient-years in the erenumab $140 \mathrm{mg}$ arm; $1[0.8 \%]$, incidence rate 3.4 per 100 patient-years with placebo) (table 4). The most commonly reported SAE in both phases of the LIBERTY study was migraine, which occurred less frequently in the OLEP phase $(2[0.8 \%]$, incidence rate 0.9 per 100 patient-years) than in the DBTP (1 [0.8\%], incidence rate 3.6 per 100 patient-years for erenumab).

Treatment discontinuation due to treatment-emergent AEs was observed in $4(1.7 \%)$ patients (1.7 per 100 patientyears, table 5) overall in the OLEP. The exposure-adjusted incidence rate of treatment-related AEs in the overall population was 30.1 per 100 patient-years (57 patients [23.8\%]) in the OLEP. The corresponding values for treatment-related AEs in the DBTP were 21 (17.8\%) with an incidence rate of 86.7 per 100 patient-years in erenumab arm and 24 (19.7\%) with an incidence rate of 95.1 per 100 patient-years in the placebo arm, respectively. The incidence of treatment-related AEs decreased in the OLEP compared with the DBTP.

During the OLEP, the incidence of treatment emergent cardiac AEs was overall low and observed in 10 (4.2\%) patients, with an incidence rate of 4.5 per 100 patient-years, in the overall $\mathrm{arm}$. The corresponding values were $1(0.8 \%)$ each for the erenumab and placebo arms in the DBTP (incidence rate 3.5 per 100 patient-years). The incidence of constipation in the LIBERTY study was low, and the exposure-adjusted incidence rates in the OLEP and DBTP were similar. Constipation was observed in 6 patients $(2.7$ per 100 patient-years) in the overall arm in the OLEP: 3 patients in the DBTP, 1 patient in the erenumab (3.6 per 100 patient-years), and 2 patients in the placebo (6.9 per
100 patient-years) arms reported constipation. No deaths were reported in the study.

There were no clinically meaningful laboratory results. Vital signs and ECG findings were reported at any time in the OLEP. These were consistent with the observations from the DBTP. $^{10}$

\section{Discussion}

In the first year of the 3-year OLEP of the LIBERTY study, the data demonstrate the long-term efficacy and safety of erenumab over a 64-week period in patients with EM (52 weeks of the OLEP) who had failed prior preventive treatment. The data show persistent efficacy, a low dropout rate, and excellent tolerability over the OLEP, which are all clinically useful outcomes for patients. Despite a dropout of 6 patients from the DBTP who did not enter the OLEP, the results were similar and sustained for the entire LIBERTY group (DBTP) and those who continued into the OLEP.

In the OLEP, the $50 \%$ responder rate for the overall population increased until weeks 37 to 40 and tended to stabilize throughout the latter part of the year. Compared with erenumab in the DBTP, an increase in the $50 \%$ response rates was observed for the overall population in the OLEP. Patients on continuous erenumab treatment showed continued efficacy for all efficacy outcomes assessed, while those patients who switched from placebo in DBTP to erenumab in the OLEP showed sustained improvement from week 13 onward. A proportional increase in efficacy over time was observed. Overall, a global trend of improvement in efficacy was observed in all treatment arms during the first year of OLEP, as well as a stabilization of the efficacy at the last 2 visits for assessment, that is, weeks 49 to 52 and weeks 61 to 64 . In addition, there was consistency of response with no wearingoff effect observed in the difficult-to-treat patient population with prior preventive treatment failures. In the OLEP, the reduction in MMD was consistent with the reduction in HIT6 score. The findings from the OLEP confirm that the efficacy observed in MMD and the response rates translate into functional improvement as observed through the improvements in the overall impact (HIT-6) and PI and EA (MPFID). These instruments are also relevant for patients with migraine and provided complementary information in the evaluation of erenumab as a migraine preventive treatment.

Most of the AEs reported in the current study were mild or moderate in severity. Nearly, $80.8 \%$ (overall arm), $76.3 \%$ (continuing erenumab), and $85.2 \%$ (initiating erenumab) of patients reported AEs in the OLEP. The corresponding incidences for SAEs were $6.7 \%, 5.9 \%$, and $7.4 \%$, respectively. Among the treatment-emergent AEs, nasopharyngitis, influenza, and back pain were the most common AEs in the OLEP in the overall population. The proportion of patients 
Table 5 Proportion of Participants With Adverse Events and the Exposure-Adjusted Subject Rate per 100 Patient-Years in the DBTP and OLEP (Open-Label Analysis Set)

\begin{tabular}{|c|c|c|c|}
\hline \multirow[b]{2}{*}{ Event } & \multicolumn{2}{|l|}{ DBTP } & \multirow{2}{*}{$\begin{array}{l}\text { OLEP } \\
\text { Overall population }(\mathrm{N}=240) \text {, } \\
\mathrm{n}(\%) / \mathrm{e}[\mathrm{r}]\end{array}$} \\
\hline & $\begin{array}{l}\text { Erenumab } 140 \mathrm{mg}(\mathrm{N}=118) \text {, } \\
\mathrm{n}(\%) / \mathrm{e}[\mathrm{r}]\end{array}$ & $\begin{array}{l}\text { Placebo }(\mathrm{N}=122) \\
\text { n (\%)/e }[r]\end{array}$ & \\
\hline Any AE & $70(59.3) / 17.4[402.6]$ & $68(55.7) / 18.0[377.9]$ & $194(80.8) / 79.9$ [242.9] \\
\hline Any SAE & $2(1.7) / 27.9[7.2]$ & $1(0.8) / 29.1[3.4]$ & $16(6.7) / 222.7[7.2]$ \\
\hline Any AE leading to discontinuation of treatment & $1(0.8) / 27.9[3.6]$ & $0(0.0) / 29.3[0.0]$ & $4(1.7) / 229.3[1.7]$ \\
\hline Any treatment-related $\mathrm{AE}$ & $21(17.8) / 24.2$ [86.7] & $24(19.7) / 25.2[95.1]$ & $57(23.8) / 189.3[30.1]$ \\
\hline Nasopharyngitis & $6(5.1) / 26.9[22.3]$ & $12(9.8) / 27.7[43.3]$ & $74(30.8) / 178.6[41.4]$ \\
\hline Influenza & - & - & $31(12.9) / 212.6[14.6]$ \\
\hline Back pain & $5(4.2) / 27.2[18.4]$ & $2(1.6) / 28.9[6.9]$ & $18(7.5) / 219.5[8.2]$ \\
\hline Injection site pain & $7(5.9) / 27.0[26.0]$ & $7(5.7) / 28.1[24.9]$ & $13(5.4) / 221.5[5.9]$ \\
\hline Fatigue & $3(2.5) / 27.4[10.9]$ & $2(1.6) / 28.8[6.9]$ & $12(5.0) / 223.0[5.4]$ \\
\hline Dizziness & $3(2.5) / 27.7[10.8]$ & $2(1.6) / 28.9[6.9]$ & $12(5.0) / 222.0[5.4]$ \\
\hline Bronchitis & $2(1.7) / 27.8[7.2]$ & $1(0.8) / 29.1[3.4]$ & $11(4.6) / 223.7[4.9]$ \\
\hline Cystitis & $1(0.8) / 27.9[3.6]$ & $2(1.6) / 28.9[6.9]$ & $11(4.6) / 224.6[4.9]$ \\
\hline Gastroenteritis & $1(0.8) / 27.9[3.6]$ & $0(0) / 29.3[0]$ & $11(4.6) / 222.9[4.9]$ \\
\hline Migraine & $1(0.8) / 27.9[3.6]$ & $2(1.6) / 28.9[6.9]$ & $10(4.2) / 224.8[4.4]$ \\
\hline Cardiac events & $1(0.8) / 28.0[3.6]$ & $1(0.8) / 29.3[3.4]$ & $10(4.2) / 224.0[4.5]$ \\
\hline Sinusitis & $1(0.8) / 27.9[3.6]$ & $1(0.8) / 29.1[3.4]$ & $10(4.2) / 224.0[4.5]$ \\
\hline Urinary tract infection & $0(0) / 28.1[0]$ & $1(0.8) / 29.1[3.4]$ & $10(4.2) / 225.9[4.4]$ \\
\hline Upper respiratory tract infection & $4(3.4) / 27.6[14.5]$ & $0(0) / 29.3[0]$ & $9(3.8) / 224.2[4.0]$ \\
\hline Constipation & $1(0.8) / 27.9$ [3.6] & $2(1.6) / 29.0[6.9]$ & $6(2.5) / 226.4[2.7]$ \\
\hline
\end{tabular}

Abbreviations: $A E$ = adverse event; DBTP = double-blind treatment phase; $\mathrm{e}=$ sum across all participants = total time at risk in the OLEP in years; $\mathrm{n}=$ number of participants reporting at least one occurrence of an adverse event in that class; $\mathrm{N}=$ number of participants in the analysis set; OLEP = open-label extension phase; $r=$ exposure-adjusted participant rate per 100 participant-years ( $n / e \times 100)$; SAE = serious AE.

Safety data reported for 1 complete year of the OLEP. Double-blind treatment (either erenumab 140 mg or placebo) was given at day 1 , week 4 , and week 8 visits, and then open-label erenumab 140 mg was given during OLEP starting from week 12 visit. Data cutoff date: week 64 or, if patient discontinued before week 64, minimum (end of study date, last patient last week 64). Time at risk during the OLEP is the time from the start of OLEP through the onset of the first event in the OLEP or the minimum (end of study date, data cutoff date, last dose +112). Time at risk during the DBTP is the time from first dose of DBTP investigational product (IP) through the onset of the first event in the DBTP or the end of the DBTP (first OLEP IP dose date or minimum [end of study date, last IP dose date +112 d] for participants who did not receive any OLEP IP dose). Cardiac events included hypertension, angina pectoris, increased blood pressure, and labile hypertension. Medical Dictionary for Regulatory Activities Version 21.1 was used for the reporting of adverse events.

with constipation was low compared to real-world data; comedications such as antidepressants and other agents that may cause constipation were largely not allowed in the trial. The basis for the disparity between real-world reports and trial data is unresolved. No deaths were reported. The safety events associated with erenumab in the OLEP was consistent with those observed in the DBTP. There were no new safety concerns observed.

The findings from this study are similar to the results of the other prior open-label extension studies conducted for erenumab. Interim analysis was performed on data from a 5-year open-label treatment phase after all patients with EM who completed 4 years in the open-label treatment phase or discontinued the study. The $>4$-year results demonstrated that erenumab was safe and well tolerated with the profile of AEs consistent with the shorter placebo-controlled studies.

Similarly, the findings from an open-label extension study in patients with CM demonstrated the long-term safety and efficacy of erenumab over a 52-week period following the 12week DBTP. ${ }^{9}$ Efficacy was continued throughout the 52 weeks. Clinically significant and meaningful reductions from DBTP baseline were observed in MMD and migraine-specific medication treatment days; overall, baseline values were reduced to about half. The safety profile in the study was consistent with the known $\mathrm{AE}$ profile of erenumab and not different from the placebo AE rates in the DBTP. ${ }^{6}$ 
The study was limited to patients with EM; therefore, results should not be generalized to include those with $\mathrm{CM}$, even though the number of $\mathrm{MMD}$ is within the range for the $\mathrm{CM}$ definition for a subset of patients. However, patients with high-frequency EM were found to be comparable to patients with CM with regard to chronicity and disability in a recently published Danish study. ${ }^{17}$ The OLEP was a nonrandomized phase with no comparator arm, and erenumab was administered open-label to the entire population without blinding of dose. A temporary technical issue related to the log pads used for daily headache reporting was observed in July 2018 that affected the collection of efficacy data for a subset of patients at the last 2 visits for assessment. Although efficacy data were available from only two-thirds of the patients at the last 2 visits due to the technical issue with the eDiary device, sensitivity analysis on these data confirmed that the findings were robust.

Patients who have been unsuccessful on prior preventive treatment failures can be difficult to treat. The LIBERTY OLEP has demonstrated sustained efficacy of erenumab treatment over 1 year in this patient population. Efficacy of erenumab was (continuously) sustained throughout 64 weeks in patients with EM who were unsuccessful on 2 to 4 prior preventive treatment failures in both the groups on continuous erenumab and those initiating erenumab treatment. The safety of erenumab was similar to the previously reported clinical trials.

\section{Acknowledgment}

The authors thank the LIBERTY study participants and investigators for their commitment to this study.

\section{Study Funding}

The research was funded by Novartis Pharma AG, Basel, Switzerland.

\section{Disclosure}

P.J. Goadsby received grants and personal fees from Amgen and Eli Lilly and Co; a grant from Celgene; personal fees from Aeon Biopharma, Alder Biopharmaceuticals, Allergan, Biohaven Pharmaceuticals Inc, Clexio, ElectroCore, eNeura, Epalex, GlaxoSmithKline, Impel Neuropharma, MundiPharma, Novartis, Pfizer, Santara Therapeutics, Sanofi, Teva Pharmaceuticals, Trigemina Inc, WL Gore, MedicoLegal work, Up-to-Date, Oxford University Press, Massachusetts Medical Society, and Wolters Kluwer; and a patent for magnetic stimulation for headache assigned to eNeura without fee. U. Reuter received consulting fees, speaking/teaching fees, and/or research grants from Allergan, Amgen, Autonomic Technologies, CoLucid, ElectroCore, Eli Lilly, Medscape, Novartis, StreamMedUp, and Teva Pharmaceuticals. M. Lanteri-Minet received grants and honoraria for advisory boards, speaker panels, or investigation studies from Allergan, Amgen, Astellas, ATI, BMS, Boehringer, Boston Scientific, CoLucid, Convergence, GlaxoSmithKline, Grünenthal, Eli Lilly, Medtronic, Menarini, MSD, Novartis, Pfizer,
Phamaleads, Reckitt Benckiser, Saint-Jude, Sanofi-Aventis, Teva Pharmaceuticals, UCB, and Zambon. P. Hours-Zesiger, C. Fernandes, S. Wen, N. Tenenbaum, and J. Klatt are employees of and hold stock in Novartis. A. Kataria is an employee of Novartis. G. Paiva da Silva Lima is an employee of and holds stock in Amgen. M.D. Ferrari received grants, consultancy, or trial support from Medtronic, ElectroCore, Amgen, Eli Lilly, Teva Pharmaceuticals. and Novartis, as well as independent support from the European Community, NWO, NIH, and the Dutch Heart Foundation. Go to Neurology.org/ $\mathrm{N}$ for full disclosures.

\section{Publication History}

Received by Neurology May 29, 2020. Accepted in final form March 5, 2021.

\section{Appendix Authors}

\begin{tabular}{lll}
\hline Name & Location & Contribution \\
\hline $\begin{array}{l}\text { Peter J. } \\
\text { Goadsby, MD }\end{array}$ & King's College London, UK & $\begin{array}{l}\text { Designed and } \\
\text { conceptualized study, was } \\
\text { the chief investigator, } \\
\text { reviewed the data and } \\
\text { drafted the manuscript, and } \\
\text { revised the manuscript for } \\
\text { intellectual content }\end{array}$ \\
\hline Uwe Reuter, & $\begin{array}{l}\text { Charité } \\
\text { Mniversitätsmedizin }\end{array}$ & $\begin{array}{l}\text { Designed and } \\
\text { conceptualized the study, } \\
\text { was the chief investigator, } \\
\text { reviewed the data and } \\
\text { drafted the manuscript, and } \\
\text { revised the manuscript for } \\
\text { intellectual content }\end{array}$ \\
& & Werlin, Germany
\end{tabular}

Michel Pain Department and FHU Was the chief investigator,
Lanteri- InovPain, CHU Nice-Côte reviewed the data, drafted Minet, MD Azur Université, France the manuscript, and revised the manuscript for intellectual content

\begin{tabular}{|c|c|c|}
\hline $\begin{array}{l}\text { Gabriel Paiva } \\
\text { da Silva } \\
\text { Lima, MD }\end{array}$ & $\begin{array}{l}\text { Amgen Inc, Thousand } \\
\text { Oaks, CA }\end{array}$ & $\begin{array}{l}\text { Reviewed the data, wrote } \\
\text { the first draft of the } \\
\text { manuscript, and revised } \\
\text { the manuscript for } \\
\text { intellectual content }\end{array}$ \\
\hline $\begin{array}{l}\text { Peggy Hours- } \\
\text { Zesiger, PhD }\end{array}$ & $\begin{array}{l}\text { Novartis Pharma AG, } \\
\text { Basel, Switzerland }\end{array}$ & $\begin{array}{l}\text { Participated in patient } \\
\text { data collection, generated } \\
\text { the statistical analysis } \\
\text { plan, drafted the } \\
\text { manuscript, and revised } \\
\text { the manuscript for } \\
\text { intellectual content }\end{array}$ \\
\hline $\begin{array}{l}\text { Chrystel } \\
\text { Fernandes, } \\
\text { PhD }\end{array}$ & $\begin{array}{l}\text { Novartis Pharma AG, } \\
\text { Basel, Switzerland }\end{array}$ & $\begin{array}{l}\text { Study biostatistician } \\
\text { responsible for the } \\
\text { statistical analyses, } \\
\text { analyzed the data, drafted } \\
\text { the manuscript, and } \\
\text { revised the manuscript for } \\
\text { intellectual content }\end{array}$ \\
\hline $\begin{array}{l}\text { Shihua Wen, } \\
\text { PhD }\end{array}$ & $\begin{array}{l}\text { Novartis Pharmaceutical } \\
\text { Corporation, East } \\
\text { Hanover, NJ }\end{array}$ & $\begin{array}{l}\text { Study biostatistician } \\
\text { responsible for the } \\
\text { statistical analyses, } \\
\text { analyzed the data, drafted } \\
\text { the manuscript, and } \\
\text { revised the manuscript for } \\
\text { intellectual content }\end{array}$ \\
\hline
\end{tabular}


Appendix (continued)

\begin{tabular}{|c|c|c|}
\hline Name & Location & Contribution \\
\hline $\begin{array}{l}\text { Nadia } \\
\text { Tenenbaum, } \\
\text { MD }\end{array}$ & $\begin{array}{l}\text { Novartis Pharmaceutical } \\
\text { Corporation, East } \\
\text { Hanover, NJ }\end{array}$ & $\begin{array}{l}\text { Generated the statistical } \\
\text { analysis plan, drafted the } \\
\text { manuscript, and revised it } \\
\text { for intellectual content }\end{array}$ \\
\hline $\begin{array}{l}\text { Aditi Kataria, } \\
\text { MPharmacy }\end{array}$ & $\begin{array}{l}\text { Novartis Healthcare Pvt. } \\
\text { Ltd, Hyderabad, India }\end{array}$ & $\begin{array}{l}\text { Interpreted the data, } \\
\text { wrote the first draft of the } \\
\text { manuscript, and revised } \\
\text { the manuscript for } \\
\text { intellectual content }\end{array}$ \\
\hline $\begin{array}{l}\text { Michel D. } \\
\text { Ferrari, MD }\end{array}$ & $\begin{array}{l}\text { Leiden University Medical } \\
\text { Centre, the Netherlands }\end{array}$ & $\begin{array}{l}\text { Was the chief investigator, } \\
\text { reviewed the data, drafted } \\
\text { the manuscript, and } \\
\text { revised the manuscript for } \\
\text { intellectual content }\end{array}$ \\
\hline Jan Klatt, MD & $\begin{array}{l}\text { Novartis Pharma AG, } \\
\text { Basel, Switzerland }\end{array}$ & $\begin{array}{l}\text { Designed and conceptualized } \\
\text { the study, reviewed the data, } \\
\text { drafted the manuscript, and } \\
\text { revised the manuscript for } \\
\text { intellectual content }\end{array}$ \\
\hline
\end{tabular}

\section{References}

1. Shi L, Lehto SG, Zhu DXD, et al. Pharmacologic characterization of AMG 334, a potent and selective human monoclonal antibody against the calcitonin gene-related peptide receptor. J Pharmacol Exp Ther. 2016;356(1):223-231.

2. Ho TW, Edvinsson L, Goadsby PJ. CGRP and its receptors provide new insights into migraine pathophysiology. Nat Rev Neurol. 2010;6(10):573-582.

3. Sun H, Dodick DW, Silberstein S, et al. Safety and efficacy of AMG 334 for prevention of episodic migraine: a randomised, double-blind, placebo-controlled, phase 2 trial. Lancet Neurol. 2016;15(4):382-390.
4. Dodick DW, Ashina M, Brandes JL, et al. ARISE: a phase 3 randomized trial of erenumab for episodic migraine. Cephalalgia. 2018;38(6):1026-1037.

5. Goadsby PJ, Reuter U, Hallstrom Y, et al. A controlled trial of erenumab for episodic migraine. N Engl J Med. 2017;377(22):2123-2132.

6. Tepper S, Ashina M, Reuter U, et al. Safety and efficacy of erenumab for preventive treatment of chronic migraine: a randomised, double-blind, placebo-controlled phase 2 trial. Lancet Neurol. 2017;16(6):425-434.

7. Ashina M, Goadsby PJ, Reuter U, et al. Sustained efficacy and long-term safety of erenumab in patients with episodic migraine: 4+ year results of a 5-year, open-label treatment period. Cephalalgia. 2019;39(1_suppl):366-367.

8. Goadsby PJ, Reuter U, Hallstrom Y, et al. One-year sustained efficacy of erenumab in episodic migraine: results of the STRIVE study. Neurology. 2020; 95(5):e469-e479.

9. Tepper SJ, Ashina M, Reuter U, et al. Long-term safety and efficacy of erenumab in patients with chronic migraine: results from a 52-week, open-label extension study. Cephalalgia. 2020;40(6):543-553.

10. Reuter U, Goadsby PJ, Lanteri-Minet M, Hours-Zesiger P, Ferrari MD, Klatt J. Efficacy and tolerability of erenumab in episodic migraine patients who previously failed 2-4 preventive treatments: a randomised placebo-controlled phase $3 \mathrm{~b}$ study. Lancet. 2018;392(10161):2280-2287.

11. Ferrari MD, Diener HC, Ning X, et al. Fremanezumab versus placebo for migraine prevention in patients with documented failure to up to four migraine preventive medication classes (FOCUS): a randomised, double-blind, placebo-controlled, phase 3b trial. Lancet. 2019;394(10203):1030-1040.

12. Mulleners WM, Kim MJ, Lainez M, et al. A randomized, placebo-controlled study of galcanezumab in patients with treatment-resistant migraine: double-blind results from the CONQUER Study. Cephalalgia. 2019;39(1 suppl):366.

13. Hepp Z, Bloudek LM, Varon SF. Systematic review of migraine prophylaxis adherence and persistence. J Manag Care Pharm. 2014;20(1):22-33.

14. Headache Classification Committee of the International Headache Society (IHS) The International Classification of headache Disorders, 3rd Edition (beta version). Cephalalgia. 2013;33(9):629-808.

15. Kosinski M, Bayliss MS, Bjorner JB. et al. A six-item short-form survey for measuring headache impact: the HIT-6. Qual Life Res. 2003;12(8):963-974.

16. Kawata AK, Hsieh R, Bender R, et al. Psychometric evaluation of a novel instrument assessing the impact of migraine on physical functioning: the Migraine Physical Function Impact Diary. Headache. 2017;57(9):1385-1398.

17. Chalmer MA, Hansen TF, Lebedeva ER, Dodick DW, Lipton RB, Olesen J. Proposed new diagnostic criteria for chronic migraine. Cephalalgia. 2020;40(4): 399-406. 


\section{Neurology}

\section{Long-term Efficacy and Safety of Erenumab: Results From 64 Weeks of the LIBERTY Study}

Peter J. Goadsby, Uwe Reuter, Michel Lanteri-Minet, et al.

Neurology 2021;96;e2724-e2735 Published Online before print April 28, 2021

DOI 10.1212/WNL.0000000000012029

This information is current as of April 28, 2021

\section{Updated Information \&} Services

References

Subspecialty Collections

Permissions \& Licensing

Reprints including high resolution figures, can be found at: http://n.neurology.org/content/96/22/e2724.full

This article cites 17 articles, 2 of which you can access for free at: http://n.neurology.org/content/96/22/e2724.full\#ref-list-1

This article, along with others on similar topics, appears in the following collection(s):

\section{Class IV}

http://n.neurology.org/cgi/collection/class_iv

Migraine

http://n.neurology.org/cgi/collection/migraine

Information about reproducing this article in parts (figures,tables) or in its entirety can be found online at:

http://www.neurology.org/about/about_the_journal\#permissions

Information about ordering reprints can be found online:

http://n.neurology.org/subscribers/advertise

Neurology ${ }^{\circledR}$ is the official journal of the American Academy of Neurology. Published continuously since 1951, it is now a weekly with 48 issues per year. Copyright Copyright ( $) 2021$ The Author(s). Published by Wolters Kluwer Health, Inc. on behalf of the American Academy of Neurology.. All rights reserved. Print ISSN: 0028-3878. Online ISSN: 1526-632X.

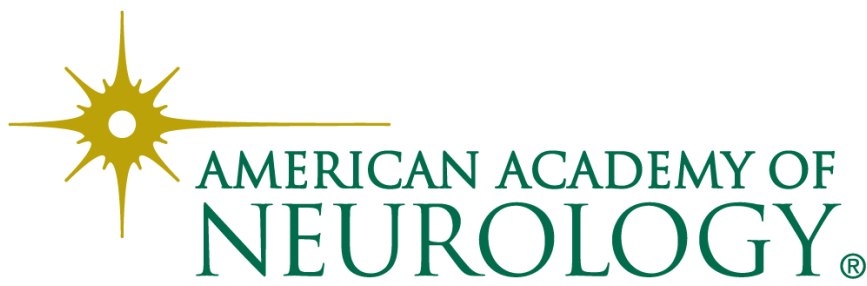

